\title{
Self-reported rather than registered cancer is associated with psychosocial strain
}

\author{
Sonja Korpimäki $i^{*}$, Markku Sumanen², Sakari Suominen ${ }^{3}$ and Kari Mattila ${ }^{2,4}$
}

\begin{abstract}
Background: Individuals with only a subjective experience of cancer may conceal severe psychological distress and act like patients with verified disease. The purpose of the study was to establish whether some typical psychosocial factors may be linked to subjects with registered cancer (confirmed) and also to those with self-reported cancer lacking accompanying registered data (non-confirmed).

Methods: The material comprised 25898 working-aged individuals (response rate 40.0\%) in 1998. Of these 19 629 also responded at the follow-up in 2003 (response rate 75.8\%). The analyses focused on respondents with cancer diagnosis in 2002 or earlier according to data of the Finnish Cancer Registry and self-report of cancer in 2003 (confirmed) $(\mathrm{N}=330)$ and on respondents with self-reported cancer only but lacking registered diagnosis (non-confirmed) $(\mathrm{N}=140)$. Those who neither reported cancer nor had a diagnosis were included as a control group ( $N=18$ 299).
\end{abstract}

Results: Respondents with confirmed cancer belonged more often to the oldest age-group than those with non-confirmed cancer. Respondents with non-confirmed cancer were more often obese, depressed and reported less social support compared to subjects with confirmed cancer. Compared to controls they had a statistically significantly increased risk of depression, lower optimism, lower life satisfaction, more childhood adversities, more negative life events and less social support.

Conclusions: Individuals with only a subjective experience of cancer reported more psychosocial strain than those with accompanying registered cancer. Self-report of a severe disease like cancer without corresponding clinical findings might reflect heavy psychological distress which should be taken into consideration in clinical work.

Keywords: Cancer, Psychosocial factors, Self-reported disease

\section{Background}

There are about 200000 people in Finland, about 4\% of the population, who have or have had cancer [1]. The yearly incidence of cancer in 2008 was for males 283.6 per 100000 person-years and for females 249.9 per 100000 person-years. The most common cancer in the industrialized countries is prostate cancer in males (4 200 new cancer cases in Finland in 2008) and breast cancer in females (4 300 new cancer cases in Finland in 2008).

The development of cancer is a long-term gradual process taking years or even decades. Cancer is a multiform disease state with very different clinical manifestation. An increasing proportion of cancer patients recover.

\footnotetext{
* Correspondence: sonja.korpimaki@uta.fi

${ }^{1}$ Tampere Health Centre, Tampere, Finland

Full list of author information is available at the end of the article
}

The common conception, nonetheless, is that cancer is a very serious possibly life threatening condition turning it to a subjectively stressful experience.

Thus, individuals with only a subjective experience of cancer may conceal severe psychological distress, potentially based on misunderstanding of the judgements given by the doctor or another representative of the health care system. These individuals may act as patients with verified disease. The purpose of the study was to establish whether some typical psychosocial factors may be linked to subjects with registered (confirmed) cancer and also to those with self-reported cancer lacking accompanying register data (non-confirmed).

\section{Methods}

The Health and Social Support Study (HeSSup) is a prospective follow-up study focussing on psychosocial

\section{Biomed Central}


determinants of health of the Finnish working-age population. The subjects belonged to a random sample drawn from the Finnish Population Register [2], stratified into four age-groups: 20-24, 30-34, 40-44 and 50-54 at baseline. In 1998 a completed postal questionnaire was returned by 25898 participants (response rate 40.0\%). Of these 19629 also responded at the follow-up in 2003 (response rate $75.8 \%$ ). Analysis of non-responders showed a good compatibility of the HeSSup sample with the Finnish population [3,4]. The concurrent joint Ethics Committee of the University of Turku and the Turku University Central Hospital considered approval not necessary for a normal cohort study, but all participants were requested to sign a consent form containing information about the study and to grant permission to allow subsequent studies with the same data set and possibility to link with national health registries.

The Finnish Cancer Registry maintains a nationwide database on all cancer cases in Finland from 1953 onwards [5]. It is also an internationally active institute for statistical and epidemiological cancer research. There were 1037 subjects in the HeSSup sample with a cancer diagnosis between the years 1955 and 2006 when the survey data was linked with data of the Cancer Registry. Of them 263 (basalioma, polycythemia vera, myelofibrosis etc.) were excluded as in the basic statistics of the Cancer Registry [6]. Thus 774 subjects having malignant cancers were included in the study. To be able to use the information within the HeSSup sample, only participants having a tumour diagnosed in 2002 or earlier were included in the analysis $(\mathrm{N}=396)$. This limitation was imposed so that recently diagnosed cancer would not influence the data collected with the 2003 questionnaire.

In the HeSSup study the participants were asked whether or not a doctor had told them that they have or have had a malignant tumour (cancer). The analyses focused on respondents who had registered cancer and also self-reported it in the follow-up survey in 2003 $(\mathrm{N}=330)$, termed "confirmed cancer", and on those who self-reported cancer only but lacked an accompanying registry diagnosis ever $(\mathrm{N}=140)$, termed "non-confirmed cancer" here (Figure 1). Those who neither reported a cancer nor had a diagnosis were included as controls ( $\mathrm{N}=18$ 299).

This study has a cross-sectional design. The analyses compared demographic, life-style and psychosocial factors asked in 2003 between respondents having confirmed cancer and non-confirmed cancer, and controls. Respondents were categorized according to gender and four age-groups: $25-29,35-39,45-49$ and 55-59 in 2003. Education, as a proxy for socioeconomic status, was ascertained by a self-report on the matriculation examination ( $\geq 12$ year education). Marital status was classified into two groups: married or cohabiting and

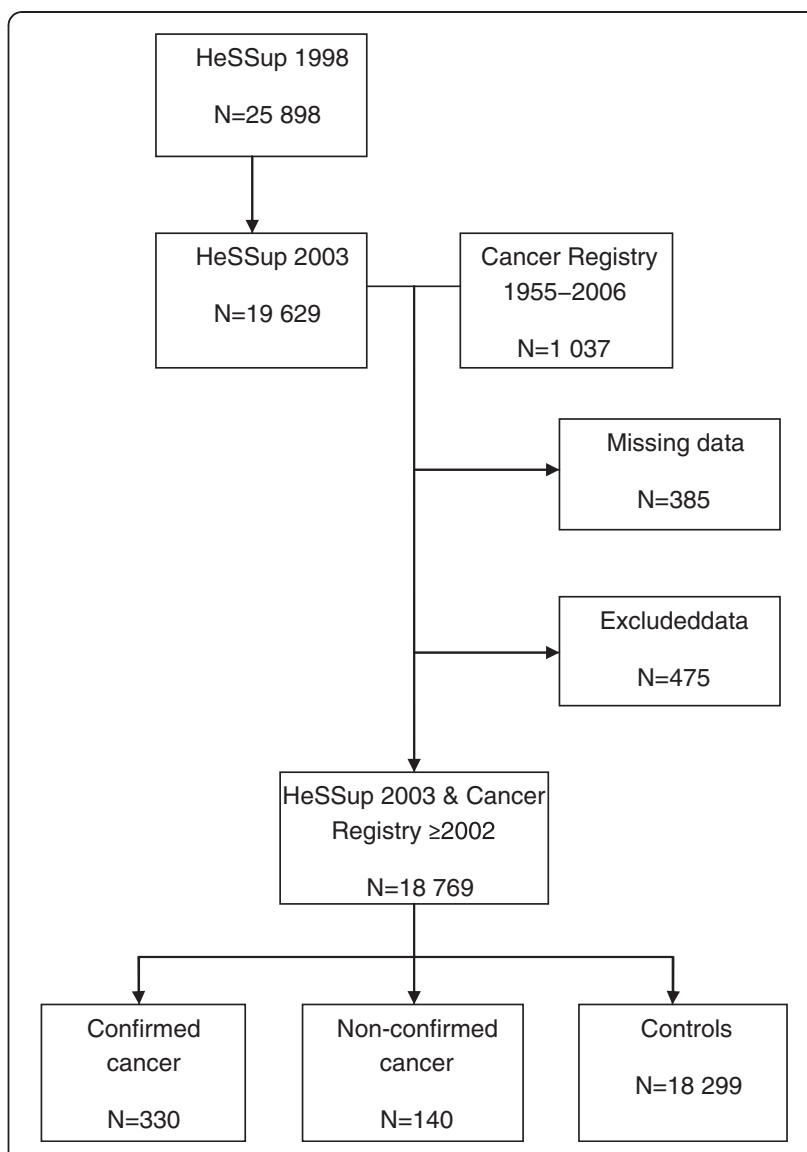

Figure 1 Flowchart representing the study population and the formation of the subjects.

single, widow or divorced. Living was graded as alone or together with one or more persons. Obesity was measured by the body mass index (BMI $<30$ or $\geq 30 \mathrm{~kg} / \mathrm{m}^{2}$ ). Participants were asked whether or not they had ever smoked and current smoking was categorized as $<5$ or $\geq 5$ cigarettes per day. Alcohol consumption was calculated as grams of alcohol per week. Weekly consumption of pure alcohol under $22 \mathrm{~g}$ was categorized as none or minimal, more than $22 \mathrm{~g}$ but less than $175 \mathrm{~g}$ in women and under 263g in men as moderate and more as heavy. Exercise activity was categorized as little (MET <2) or much (MET $\geq 2$ ) according to daily exercise [7].

The general sense of stressfulness was measured by the Reeder Stress Inventory [8]. This comprises the following four statements: "In general I am usually tense or nervous", "There is a great amount of nervous strain connected with my daily activities", "At the end of the day I am completely exhausted mentally and physically" and "My daily activities are extremely trying and stressful." Participants indicate the extent to which each statement applies to them using a 5-point Likert scale. The score was calculated as the overall sum of the four items 
(range 4-20). The sum was classified into three: little $(\geq 17)$, moderate $(12-17)$ or great $(\leq 12)$.

Symptoms of depression were assessed by the widely used 21-item Beck Depression Inventory [9]. A sum score over the cut-off value of 19 was taken to indicate (moderate or severe) depressiveness.

Hostility was assessed by a three-item expressed hostility scale [10]. This included respondents' self-ratings of irritability, ease of anger-arousal, and argumentativeness, which were rated on a 5-point Likert scale. The hostility scale was built up by the sum score on these three items (total range 3-15) and categorized into three classes $(0-5,6-12$ or $13-15)$.

The level of optimism was measured by the Life Orientation Test-Revised (LOT-R) [11]. This is a 6-item scale covering generalized future expectations; three items are worded positively and three negatively, and the items are presented as a 5-point Likert scale. The LOT-R scale was reconstructed by summing (total 6-30) and categorized into three classes $(<20,20-24$ or $>24)$.

Life satisfaction was determined by the responses to four questions dealing with interest in life, happiness, general ease of living and loneliness [12]. The range of the sum score for life satisfaction (LS) was 4-20. An increase in values indicated a decrease in life satisfaction: satisfied (LS 4-6), intermediate group (LS 7-11) or dissatisfied (LS 12-20).

Subjects were asked to recall their childhood adversities in terms of six questions: "Did your parents divorce?", "Did your family have long-lasting economic difficulties?", "Did serious conflicts arise in your family?", "Were you often afraid of some member of your family?", "Was someone in the family seriously or chronically ill?" and "Did someone in the family have problems with alcohol?" [13]. Alternative answers were Yes, No or I do not know. Only the first two options were included in the statistical analyses. The number of childhood adversities per individual was calculated $(0,1$ or $2-6)$.

Respondents were also requested to recall life events. Adverse events were asked via a 21-item question sequence considering e.g. death or illness of close person, divorce, loss of job, accidents and violence $[14,15]$. The sum was classified into two groups: few $(0-2)$ or many $(>2)$. Likewise positive events were ascertained from answers to the question "Has some remarkable positive experience or event happened to you?" The eight response options were: in family life, in working life, in human relationships, in spiritual life, in economic situation, in living, in hobbies and in love. The sum was classified into two groups: few $(0-2)$ or many $(>2)$.

Social support was estimated by the Brief Social Support Questionnaire [16]. It comprises six questions: "Whom can you really trust when you want to forget your sorrow when feeling stressed?", "Whose help can you really count on when needing relaxation under pressure?", "Who really accepts you with all your strengths and weaknesses?", Who really cares about you whatever happens?", "Who can you really trust to get you to feel better when upset?" and "Whom can you count on to comfort you when you are screwed up?". Each of the questions gave zero to six sources of support to select from. The sum score (0-36) was classified: $0-5,6-11$, $12-17$ or $\geq 18$. Low social support was indicated by the lowest class. The type of social support was based on the mean of options: "I get more support than I give", "I give more support than I get" or "I get as much support as I give" to questions considering the three most important adults in question.

The statistical significance of differences between respondents having confirmed and non-confirmed cancer was tested by $\chi^{2}$ test. Odds ratios (OR) with $95 \%$ confidence interval (CI) for cancer in the multivariate logistic regression analysis were calculated in both groups for demographic, life-style and psychosocial factors with adjustment for age and sex. The analyses were made using SPSS for Windows, release 13.

\section{Results}

The majority of the study population were women, while age was evenly distributed (Table 1). A minority among the respondents had a higher educational level. Most were married or cohabiting and lived with one or more persons. Their life-style was on average healthy: BMI equal to 30 or over marking obesity was noted in one respondent out of four, regular smoking was reported by one in five, heavy alcohol drinking by one in twenty and little exercise by one in four. Moderate or severe depression came up in $4.3 \%$ of reports. The feelings of stress, hostility, optimism and satisfaction with life were mostly expressed as moderate. Over half of the respondents graded their social support in the first or second category, indicating minor support. The prevailing type of social support was "getting more than giving". No childhood adversities had been experienced by $39 \%$; on the other hand nearly the same proportion had experienced many. Of all respondents $78 \%$ reported only few negative events. Many positive events were reported by $88 \%$.

There were no statistically significant differences in gender between respondents having confirmed and nonconfirmed cancer but those with confirmed cancer belonged more often to the oldest age-group analyzed $(\mathrm{p}<0.001)$ (Table 2). The sociodemographic indicators education, marital status and number of people living in the same household showed no differences. The subjects with non-confirmed cancer were more often obese $(\mathrm{p}=0.003)$ than those with confirmed cancer. Life-style factors such as smoking, alcohol consumption and exercise activity were equally reported. Depression was more 
Table 1 Distribution of demographic, life-style and psychosocial factors among the study population ( $N=18769$ )

\begin{tabular}{ccc}
\hline & N & $\%$ \\
\hline Gender & & \\
Female & 11519 & 61.4 \\
Male & 7247 & 38.6
\end{tabular}

Age-group

$\begin{array}{ll}55-59 & 4984 \\ 45-49 & 4649 \\ 35-39 & 4336 \\ 25-29 & 4797\end{array}$

Education

Lower

10412

Higher

8332

Marital status

Marriage/cohabitation

Single/widow/divorced

Living

With $\geq 1$ persons

With 0 persons

Obesity

$\mathrm{BMl}<30$

$\mathrm{BMl} \geq 30$

Smoking

No

Quitted

Regular ( $<5$ cigarettes/day)

Regular ( $\geq 5$ cigarettes/day)

Alcohol use

None or minimal

Moderate

Heavy

Exercise activity

Much (met $\geq 2$ )

Little (met $<20$

Stress

Low

Moderate

High

Depression

Beck 0-19

Beck $\geq 20$

Hostility

Low

Moderate

High
12838

5909

15116

3.439

13917

4519

8227

5163

416

3410

6161

11523

1043

13430

5222

5113

9242

4217

17631

787

3913

10483

4245
55.5

44.5

68.5

31.5

81.5

18.5

75.5

24.5

32.9

61.5

5.6
Table 1 Distribution of demographic, life-style and psychosocial factors among the study population ( $N=18$ 769) (Continued)

Optimism

High

5747

30.9

Low

9242

49.7

3590

19.3

Life satisfaction

High

4568

24.5

10553

56.7

Low

3498

18.8

Childhood adversities ( $n$ )

$$
0
$$

7325

39.2

1

4863

26.0

2-6

6513

Negative events

Few (0-2)

14515

77.7

Many (>2)

4158

22.3

Positive events

Many (>2)

16216

87.9

Few 90-2)

2232

12.1

Social support (points)

$$
\geq 18
$$

1682

9.0

12-17

5008

26.7

6-11

10212

54.4

0-5

1867

Support type

\begin{tabular}{lll} 
Gets as much as gives & 6010 & 32.5 \\
Gets more than gives & 7170 & 38.8 \\
Gets less than gives & 5284 & 28.6 \\
\hline
\end{tabular}

common among subjects having non-confirmed cancer than among those with confirmed cancer $(\mathrm{p}=0.044)$. This group also reported less social support $(\mathrm{p}<0.001)$ but its type showed no difference. Likewise reporting of other examined psychosocial factors, including number of life events, did not differ.

In the multivariate regression analyses with adjustment for age and sex, single, widowed or divorced respondents and also respondents living alone had more confirmed cancer than controls (Table 3). Subjects whose educational level was lower had increased likelihood to have non-confirmed cancer. Single, widowed or divorced respondents also had more non-conformed cancer whereas those who lived alone had not. Obesity seemed to increase the risk for reporting non-confirmed cancer twofold. Regular and heavier smoking likewise increased this risk. Neither alcohol use nor exercise activity had effects on the likelihood of confirmed or non-confirmed cancer. 
Table 2 Distribution of demographic, life-style and psychosocial factors among respondents having registered (confirmed cancer) and only self-reported cancer (non-confirmed cancer)

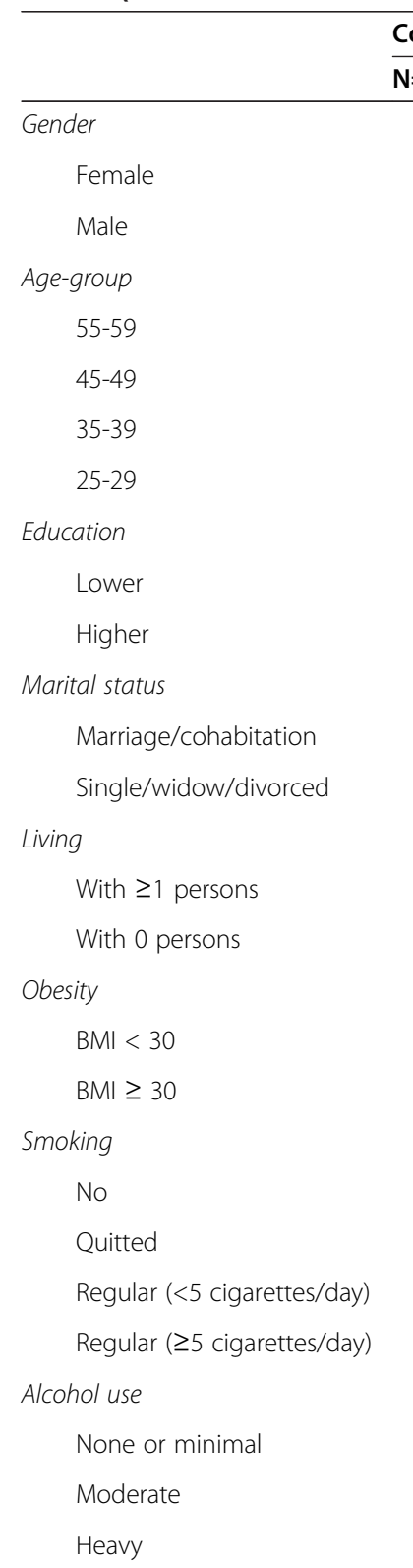

Exercise activity

Much (met $\geq 2$ )

Little (met $<2)$

Stress

Low

High

Depression

Beck 0-19

Beck $\geq 20$
Confirmed Non-confirmed P-value

$\mathrm{N}=330 \% \quad \mathrm{~N}=140 \%$

$73.9 \quad 72.1$

26.1

27.9

58.8

42.9

27.3

8.8

26.4

20.7

4.8

10.0

64.5

35.5

69.6

30.4

70.3

29.7

71.4

28.6

76.5

23.5

23.2

70.9

56.7

29.1

43.3

46.8

35.1

1.6

16.6

40.1

55.7

4.3

71.0

29.0

68.6

31.4

42.4

28.8

2.4

26.4

40.7

52.1

7.1

0.593

0.408

0.105

0.947

$$
\text { Few (0-2) }
$$

Few (0-2)
Social support (points)

$\geq 18$
$12-17$
$6-11$
$0-5$

\section{Support type}

\section{Negative events
Few (0-2)}

Gets as
Gets more than gives
Gets less than gives

Confirmed cancer was seen only in the context of low life satisfaction and many negative life events in the background (Table 4). In the case of non-confirmed cancer, however, a statistically significantly increased risk was seen in the context of most psychosocial factors analyzed. The likelihood in cases of depression was 2.75 (95\% CI 1.62-4.66), in cases with low optimism 2.02 (95\% CI 1.26-3.24) and with low life satisfaction 1.80 (95\% CI 1.20-2.96) compared to controls. Reported childhood adversities were associated with non-confirmed cancer; both in the case of one or 2-6 adversities. Adverse life events showed an association with report of 
Table 3 ORs $(95 \% \mathrm{CI})$ of demographic and life-style factors reported among respondents in the multivariate logistic regression analysis for registry-confirmed (confirmed cancer) and only self-reported cancer (non-confirmed cancer) with adjustment for age and sex

\begin{tabular}{|c|c|c|c|c|}
\hline & \multicolumn{2}{|c|}{ Confirmed $\sim$ control } & \multicolumn{2}{|c|}{ Non-confirmed $\sim$ control } \\
\hline & $\overline{O R}$ & $95 \% \mathrm{Cl}$ & OR & $95 \% \mathrm{Cl}$ \\
\hline \multicolumn{5}{|l|}{ Education } \\
\hline Higher & 1 & & 1 & \\
\hline Lower & 0.913 & $0.719-1.159$ & 1.523 & $1.039-2.232$ \\
\hline \multicolumn{5}{|l|}{ Marital status } \\
\hline Marriage /cohabitation & 1 & & 1 & \\
\hline Single/widow/divorced & 1.384 & $1.083-1.768$ & 1.596 & $1.119-2.274$ \\
\hline \multicolumn{5}{|l|}{ Living } \\
\hline With $\geq 1$ persons & 1 & & 1 & \\
\hline With 0 persons & 1.366 & $1.050-1.777$ & 1.431 & $0.957-2.138$ \\
\hline \multicolumn{5}{|l|}{ Obesity } \\
\hline $\mathrm{BMI}<30$ & 1 & & 1 & \\
\hline $\mathrm{BMI} \geq 30$ & 1.024 & $0.799-1.311$ & 2.120 & $1.497-3.003$ \\
\hline \multicolumn{5}{|l|}{ Smoking } \\
\hline No & 1 & & 1 & \\
\hline Quitted & 1.219 & $0.941-1.579$ & 1.105 & $0.718-1.700$ \\
\hline Regular ( $<5$ cigarettes/day) & 0.910 & $0.369-2.249$ & 1.326 & $0.411-4.277$ \\
\hline Regular ( $\geq 5$ cigarettes/day) & 0.989 & $0.713-1.372$ & 1.652 & $1.062-2.571$ \\
\hline \multicolumn{5}{|l|}{ Alcohol use } \\
\hline None Or minimal & 1 & & 1 & \\
\hline Moderate & 0.835 & $0.661-1.055$ & 0.754 & $0.527-1.077$ \\
\hline Heavy & 0.655 & $0.373-1.151$ & 1.100 & $0.553-2.190$ \\
\hline \multicolumn{5}{|l|}{ Exercise activity } \\
\hline Much (met $\geq 2$ ) & 1 & & 1 & \\
\hline Little (met<2) & 0.904 & $0.708-1.153$ & 1.083 & $0.755-1.553$ \\
\hline
\end{tabular}

non-confirmed cancer similar to that with confirmed cancer. Little social support was associated with reporting non-confirmed cancer (OR 2.69, 95\% CI 1.20-6.06), but the interrelationship between receiving and giving support showed no association.

\section{Discussion}

According to our findings psychosocial strain appeared to accumulate among subjects who had only subjective, i.e. non-confirmed cancer. They had an increased risk of depression, lower optimism, lower life satisfaction, more childhood adversities, more negative life events and less social support as compared to individuals with by means of registry data confirmed cancer. Thus, the results gave support for the pre-assumption that individuals with a subjective experience of cancer that has not been a provisional diagnosis nor has been based on missing or invalid registry data may conceal severe psychological distress. That kind of situation might partially be based on misunderstanding of the message given by a health care professional. They also had more often a lower educational level, were single, widowed or divorced, and were obese and regular heavier smokers.

\section{Strengths}

The HeSSup sample may be regarded as sufficiently large and the response rate to the follow-up as high (75.8\%). According to the kappa coefficient the consistency of responses on childhood adversities between the years 1998 and 2003 was good [17,18]. The consistency of some other psychosocial variables asked may be comparably stable, whereas some other self-reports may be more prone to reactivity. The measured variables can be considered valid, since they are widely used in well organized and referred studies [8-16].

The cancer diagnoses in our material can be considered reliable and extensive. The data quality and quality control of the Finnish Cancer Registry is valid [19], and it is highly confident that all diagnosed cancer cases were registered and those who only self-reported cancer 
Table 4 ORs $(95 \% \mathrm{Cl})$ of psychosocial factors reported among respondents in the multivariate logistic regression analysis for registry-confirmed (confirmed cancer) and only self-reported cancer (non-confirmed cancer) with adjustment for age and sex

\begin{tabular}{|c|c|c|c|c|}
\hline & & ontrol & & control \\
\hline & OR & $95 \% \mathrm{Cl}$ & OR & $95 \% \mathrm{Cl}$ \\
\hline Stress & & & & \\
\hline Low & 1 & & 1 & \\
\hline Moderate & 1.090 & $0.840-1.415$ & 1.052 & $0.686-1.612$ \\
\hline High & 0.964 & $0.701-1.326$ & 1.553 & $0.979-2.463$ \\
\hline Depression & & & & \\
\hline Beck 0-19 & 1 & & 1 & \\
\hline Beck $\geq 20$ & 1.291 & $0.813-2.051$ & 2.749 & $1.620-4.664$ \\
\hline Hostility & & & & \\
\hline Low & 1 & & 1 & \\
\hline Moderate & 0.998 & $0.763-1.306$ & 1.279 & $0.716-1.724$ \\
\hline High & 1.144 & $0.816-1.605$ & 1.068 & $0.616-1.850$ \\
\hline Optimism & & & & \\
\hline High & 1 & & 1 & \\
\hline Moderate & 0.877 & $0.682-1.129$ & 1.256 & $0.820-1.924$ \\
\hline Low & 1.126 & $0.827-1.533$ & 2.018 & $1.258-3.239$ \\
\hline Life satisfaction & & & & \\
\hline High & 1 & & 1 & \\
\hline Moderate & 1.236 & $0.923-1.657$ & 1.117 & $0.716-1.724$ \\
\hline Low & 1.510 & $1.069-2.131$ & 1.800 & $1.096-2.957$ \\
\hline Child adversities (n) & & & & \\
\hline 0 & 1 & & 1 & \\
\hline 1 & 1.085 & $0.818-1.439$ & 1.594 & $1.022-2.486$ \\
\hline $2-6$ & 1.211 & $0.935-1.570$ & 1.761 & $1.167-2.655$ \\
\hline Negative events & & & & \\
\hline Few (0-2) & 1 & & 1 & \\
\hline Many (>2) & 1.486 & $1.160-1.903$ & 1.616 & $1.124-2.322$ \\
\hline Positive events & & & & \\
\hline Many (>2) & 1 & & 1 & \\
\hline Few (0-2) & 1.087 & $0.801-1.475$ & 0.994 & $0.600-1.648$ \\
\hline Social support (points) & & & & \\
\hline$\geq 18$ & 1 & & 1 & \\
\hline $12-17$ & 1.195 & $0.775-1.845$ & 0.770 & $0.334-1.775$ \\
\hline $6-11$ & 0.839 & $0.553-1.272$ & 1.748 & $0.841-3.635$ \\
\hline $0-5$ & 0.689 & $0.999-1.181$ & 2.693 & $1.197-6.060$ \\
\hline Support type & & & & \\
\hline Gets as much as gives & 1 & & 1 & \\
\hline Gets more than gives & 1.254 & $0.953-1.651$ & 1.071 & $0.687-1.669$ \\
\hline Gets less than gives & 0.804 & $0.618-1.045$ & 1.315 & $0.889-1.946$ \\
\hline
\end{tabular}


did not have a verified diagnosis. The agreement between questionnaire data and medical records has proved to be good in chronic diseases with clear diagnostic criteria, while for diseases with no established diagnostic criteria it seemed poor [20]. When only definite diagnoses were included, questionnaire responses indicated a higher prevalence.

\section{Limitations}

Misinterpretations of cancer diagnoses may have originated from doctors' wording when questioning or excluding something during the examination, e.g. nevus extraction, prostate sample or Pap test. A provisional diagnosis is not subsequently confirmed upon more extensive work-up, after the patient was told that cancer was present. To reduce false interpretations, cancer types like basalioma, polycythemia vera and myelofibrosis were excluded, as they are in the basic statistics of the Cancer Registry. These cancers are usually only monitored, not actively treated. The word cancer may even today sound frightening. Hunziker and associates concluded that one in three "asymptomatic" patients had one or more hidden reasons for requesting a checkup [21]. One concern for a consultation might be a fear of cancer.

The analyses were adjusted for age and sex, but one further notable variable for adjustment might have been depression. The diagnosis of cancer was associated with depression, but the extent has varied in previous studies [22-24]. In our study depression was associated with reporting non-confirmed cancer, not with confirmed disease. Romanov and associates found that somatic disease, stressful life events and lack of social support each independently increased the risk of depressiveness [15]. Strömberg and associates found that perceived physical health, stress, family relations and work situation are relevant indicators in detection of patients at risk of depression in primary care settings [25]. One limitation in our study was the cross-sectional assessment of these and other psychosocial variables in the questionnaire.

To avoid the impact of recently diagnosed cancer on responses to the questionnaire in 2003, only cancers diagnosed in 2002 or earlier were included. No causal relationship between the psychosocial variables and the cancer diagnosis can be assumed. Here we could not know when e.g. negative life events have occurred, or whether the diagnosis changed life satisfaction or the feeling of social support. Factors such as time since diagnosis and treatment, type of treatment or possible cancer recurrence were not included in the analyses. This notwithstanding, Parker and colleagues found that disease characteristics appeared to have less impact on patients' quality of life than did demographic variables or social support [23]. Hamer and associates showed that the presence of participants with a cancer history in community-based cohorts may lead to overestimation of the association between psychosocial distress and subsequent cancer mortality [26].

\section{Comparison to other studies}

Psychosocial factors may contribute to cancer via highrisk life style factors. No such notable effect was seen either in our study or in the work of Chida and associates [27]. An increased likelihood of a confirmed cancer diagnosis was seen only in the context of low life satisfaction and a great number of negative life events in the background.

Socioeconomic status was measured in terms of education, which was lower among respondents who had non-confirmed cancer. Pukkala and Weiderpass found cancers of the cervix uteri and vagina to be associated with lower social class, whereas breast cancers were most common in higher social classes [28]. Living without a close relationship increased the risk of confirmed cancer here. Partner support was associated with high optimism and less despair in cancer patients [29]. Mortality has been estimated to be lowest at about 22-25 kg/m $\mathrm{m}^{2}$ BMI and each $5 \mathrm{~kg} / \mathrm{m}^{2}$ higher BMI has been associated with $10 \%$ higher mortality due to malignancies [30]. In our study obesity was associated only with reporting non-confirmed cancer. Smoking as a known risk factor for many types of cancer also replicated this finding, but not for confirmed disease. This was not surprising, since after confronting a disease people might be more prone to change their habits. In a recently published survey covering life-style behaviours among cancer survivors, males did not differ from controls and females were only more physically inactive [31].

Traeger and associates found that prostate cancer patients who experienced more daily stress may have poorer resources to cope with ongoing disease concerns [32]. In our study no difference in reported stress was seen between both groups of cancer patients and controls. The better psychosocial adaptation in women with breast cancer under treatment may affect biological parameters and may contribute to their health status [33]. Baider and associates found that cancer patients and also partners experiencing high psychosocial distress reported lower levels of perceived family support [34]. Our results are in accordance with this. Quality of life among cancer patients was shown to correlate with psychosocial variables, whereas no clear causation was seen in the work of Shapiro and associates [35]. Lebel and associates concluded that earlier stress-related problems during diagnosis and treatment predicted long-term stress-related problems among breast cancer patients [36]. 
Somatoform disorders like hypochondria may also explain the subjective experience of cancer. Haftgoli and associates examined the association with psychosocial stressors and depression, anxiety and somatoform disorders in primary care patients consulting GP for a physical complaint [37]. Stressors appeared to have less impact on levels of somatoform disorders than on depression or anxiety.

\section{Conclusions}

Individuals with only a subjective experience of cancer reported more psychosocial strain than those with accompanying registered cancer. People with experience of having cancer but no verified diagnosis may act like cancer patients. Their need for health care services might increase. Doctors should not undertake groundless examinations or make even hazardous, harmful or injurious decisions. Instead such patients should be given support and their possible depressiveness should be treated. Self-report of a severe disease like cancer without corresponding clinical findings might reflect heavy psychological distress which should be taken into consideration in clinical work.

\section{Competing interests}

The authors declare that they have no competing interests.

\section{Authors' contributions}

SK performed the statistical analysis and drafted the manuscript. MS participated in the design of the study and helped to draft the manuscript. SS conceived the study and helped to revise the manuscript. KM conceived the study, and participated in its design and coordination and helped to draft the manuscript. All authors have read and approved the final manuscript.

\section{Author details}

${ }^{1}$ Tampere Health Centre, Tampere, Finland. ${ }^{2}$ Medical School, University of Tampere, Tampere, Finland. ${ }^{3}$ Department of Public Health, Nordic School of Public Health, University of Turku, Turku, Finland. ${ }^{4}$ Centre of General Practice, Hospital District of Pirkanmaa, Tampere, Finland.

Received: 18 April 2012 Accepted: 7 November 2012 Published: 13 November 2012

\section{References}

1. The Finnish Cancer Registry: Institute for Statistical and Epidemiological Cancer Research. Helsinki, Finland: [http://stats.cancerregistry.fi/stats/fin/ vfin0008i0.html] (accessed December 2010).

2. Population Register Centre: Helsinki, Finland: http://www.vrk.fi/default.aspx? site=4] (accessed August 2012).

3. Korkeila K, Suominen S, Ahvenainen J, Ojanlatva A, Rautava P, Helenius H, Koskenvuo M: Non-response and related factors in a nation-wide health survey. Eur J Epidemiol 2001, 17(11):991-999.

4. Suominen S, Koskenvuo K, Sillanmäki L, Vahtera J, Korkeila K, Kivimäki M, Mattila K, Virtanen P, Sumanen M, Rautava P, Koskenvuo M: Non-response in a nationwide follow-up postal survey in Finland: a register-based mortality analysis of respondents and non-respondents of the Health and Social Support (HeSSup) Study. BMJ Open 2012, 2:e000657.

5. Finnish Cancer Registry: Institute for Statistical and Epidemiological Cancer Research: Cancer in Finland 2008 and 2009, Cancer Statistics of the National Institute for Health and Welfare (THL). Helsinki: Cancer Society of Finland Publication No. 84; 2011. [www.cancer.fi/syoparekisteri/en/] (accessed August 2012).

6. The Finnish Cancer Registry: Institute for Statistical and Epidemiological Cancer Research. Helsinki, Finland. [http://www.cancer.fi/syoparekisteri/en/ registration] (accessed August 2012).
7. Wilson PW, Paffenbarger RS Jr, Morris JN, Havlik RJ: Assessment methods for physical activity and physical fitness in population studies: report of a NHLBI workshop. Am Heart J 1986, 111(6):1177-1192.

8. Reeder LG, Schrama PG, Dirken JM: Stress and cardiovascular health: an international cooperative study. I. Soc Sci Med 1973, 7(8):573-584

9. Beck AT, Ward CH, Mendelson M, Mock J, Erbaugh J: An inventory for measuring depression. Arch Gen Psychiatry 1961, 4(6):561-571.

10. Koskenvuo M, Kaprio J, Rose RJ, Kesäniemi A, Sarna S, Heikkilä K, Langinvainio $\mathrm{H}$ : Hostility as a risk factor for mortality and ischemic heart disease in men. Psychosom Med 1988, 50(4):330-340.

11. Scheier MF, Carver CS, Bridges MW: Distinguishing optimism from neuroticism (and trait anxiety, self-mastery, and self-esteem): a reevaluation of the Life Orientation Test. J Pers Soc Psychol 1994 67(6):1063-1078.

12. Koivumaa-Honkanen $H$, Honkanen R, Viinamäki H, Heikkilä K, Kaprio J, Koskenvuo M: Self-reported life satisfaction and 20-year mortality in healthy Finnish adults. Am J Epidemiol 2000, 152(10):983-991.

13. Rahkonen O, Lahelma E, Huuhka M: Past or present? Childhood living conditions and current socioeconomic status as determinants of adult health. Soc Sci Med 1997, 44(3):327-336

14. Kivimäki M, Vahtera J, Elovainio M, Lillrank B, Kevin MV: Death or illness of a family member, violence, interpersonal conflict, and financial difficulties as predictors of sickness absence: longitudinal cohort study on psychological and behavioral links. Psychosom Med 2002, 64(5):817-825.

15. Romanow K, Varjonen J, Kaprio J, Koskenvuo M: Life events and depressiveness - the effect of adjustment for psychosocial factors, somatic health and genetic liability. Acta Psychiatr Scand 2003, 107(1):25-33.

16. Sarason IG, Sarason BR, Shearin EN, Pierce GR: A brief measure of social support: practical and theoretical implications. J Soc Pers Relatsh 1987, 4(4):497-510.

17. Sumanen M, Koskenvuo M, Sillanmäki L, Mattila K: Childhood adversities experienced by working-aged coronary heart disease patients. J Psychosom Res 2005, 59(5):331-335.

18. Korpimäki S, Sumanen M, Sillanmäki L, Mattila K: Cancer in working-age is not associated with childhood adversities. Acta Oncol 2010, 49(4):436-440.

19. Teppo L, Pukkala E, Lehtonen M: Data quality and quality control of a population-based cancer registry. Experience in Finland. Acta Oncol 1994, 33(4):365-369.

20. Haapanen N, Miilunpalo S, Pasanen M, Oja P, Vuori I: Agreement between questionnaire data and medical records of chronic diseases in middle-aged and elderly Finnish men and women. Am J Epidemiol 1997, 145(8):762-769.

21. Hunziker S, Schläpfer M, Langewitz W, Kaupfann G, Nüesch R, Battegay E, Zimmerli U: Open and hidden agendas of "asymptomatic" patients who request check-up exams. BMC Fam Pract 2011, 12:22.

22. Grassi L, Rosti G: Psychosocial morbidity and adjustment to illness among long-term cancer survivors. Psychosomatics 1996, 37(6):523-532.

23. Parker PA, Baile WF, De Moor C, Cohen L: Psychosocial and demographic predictors of quality of life in a large sample of cancer patients. Psychooncology 2003, 12(2):183-193.

24. Oerlemans ME, van den Akker M, Schuurman AG, Kellen E, Buntinx F: A meta-analysis on depression and subsequent cancer risk. Clin Prac Epidemiol Mental Health 2007, 3:29.

25. Strömberg R, Backlund LG, Löfvander M, Psychosocial stressors and depression at a Swedisch primary health care centre: A gender perspective study. BMC Fam Pract 2011, 12:120.

26. Hamer M, Yoichi C, Molly GJ: Psychological distress and cancer mortality. J Psychosom Res 2009, 66(3):255-258.

27. Chida Y, Hamer M, Wardle J, Steptoe A: Do stress-related psychosocial factors contribute to cancer incidence and survival? Nature Clin Pract 2008, 5(8):466-475

28. Pukkala $\mathrm{E}$, Weiderpass $\mathrm{E}$ : Time trends in socio-economic differences in incidence rates of cancers of the breast and female genital organs (Finland, 1971-1995). Int J Cancer 1999, 81(1):56-61.

29. Gustavsson-Lilius M, Julkunen J, Hietanen P: Quality of life in cancer patients: The role of optimism, hopelessness, and partner support. Qual Life Res 2007, 16(1):75-87.

30. Prospective studies collaboration, Whitlock $G$, Lewington $S$, Sherliker $P$, Clarke R, Emberson J, Halsey J, Qizilbash N, Collins R, Peto R: Body-mass 
index and cause-specific mortality in 900000 adults: collaborative analyses of 57 prospective studies. Lancet 2009, 373(9669):1083-1096.

31. Linsky A, Nyambose J, Battaglia TA: Lifestyle behaviors in Massachusetts adult cancer survivors. J Cancer Surviv 2011, 58(1):27-34.

32. Traeger L, Penedo FJ, Gonzalez JS, Dahn JR, Lechner SC, Schneiderman N, Antoni MH: Illness perceptions and emotional well-being in men treated for localized prostate cancer. J Psychosom Res 2009, 67(5):389-397.

33. Blomberg BB, Alvarez JP, Diaz A, Romero MG, Lechner CS, Carver CS, Holley H, Antoni MH: Psychosocial adaptation and cellular immunity in breast cancer patients in the weeks after surgery: An exploratory study. J Psychosom Res 2009, 67(5):369-376.

34. Baider L, Ever-Hadani P, Goldzweig G, Wygoda MR, Peretz T: Is perceived family support a relevant variable in psychological distress? A sample of prostate and breast cancer couples. J Psychosom Res 2003, 55(5):453-460.

35. Shapiro SL, Lopez AM, Schwartz GE, Bootzin R, Figueredo AJ, Braden CJ, Kurker SF: Quality of life and breast cancer: Relationship to psychosocial variables. J Clin Psychol 2001, 57(4):501-519.

36. Lebel $\mathrm{S}$, Rosberger Z, Edgar L, Devins GM: Predicting stress-related problems in long-term breast cancer survivors. J Psychosom Res 2008, 65(6):513-523.

37. Haftgoli N, Favrat B, Verdon F, Vaucher P, Bischoff T, Burnand B, Herzig L: Patients presenting with somatic complaints in general practice: depression, anxiety and somatoform disorders are frequent and associated with psychosocial stressors. BMC Fam Pract 2010, 11:67.

doi:10.1186/1471-2296-13-107

Cite this article as: Korpimäki et al:: Self-reported rather than registered cancer is associated with psychosocial strain. BMC Family Practice 2012 13:107.

\section{Submit your next manuscript to BioMed Central and take full advantage of:}

- Convenient online submission

- Thorough peer review

- No space constraints or color figure charges

- Immediate publication on acceptance

- Inclusion in PubMed, CAS, Scopus and Google Scholar

- Research which is freely available for redistribution 